\title{
Innovation Design and Development of PET Plastic Waste Processing Machines by Extruder Method
}

\author{
Hadi Pranoto ${ }^{a^{*}}$, Zainal Arifin ${ }^{b}$, and Henry Carles ${ }^{a}$ \\ aDepartment of Mechanical Engineering, Faculty of Engineering, Universitas Mercu Buana, Jakarta, Indonesia \\ ${ }^{b}$ Departement of Automotive Engineering, Universitas Negeri Yogyakarta, Indonesia
}

\begin{abstract}
According to the Ministry of Environment (KLH), Indonesia's average population produces 189 thousand tons of garbage per day. Of this amount, $15 \%$ is plastic waste or 28.4 thousand tons of plastic waste per day. The famous handling of plastic waste is $3 \mathrm{R}$ (Reduce, Reuse, Recycle). Reduce is reducing the purchase or use of goods made from plastic, especially disposable items. Reuse is the repeated use of plastic-based items. Recycle is recycling goods made of plastic. The method used in this design study is to use SolidWorks software by combining the literature study VDI221 to obtain a variant of the design results that will be used. The study results do a plastic bench machine that is integrated to produce plastic seeds, which are PET-shaped, which are extruded in a device that has been brewed. From the results of the design in the data processing and design specifications of the PET plastic waste-processing machine with the extruder method, the construction consists of several units, namely, Shredder unit, Extruder unit, Cutter unit, and Machine frame. The shredder unit serves to destroy plastic waste that is still intact in pieces before being processed in the extruder unit. The extruder unit functions to melt PET waste to be extruded using a screw. The cutter unit operates to cut processed extrusion waste into pellet granules. The engine frame is used to support the entire engine unit. The results of the Plastic Waste Extruder Machine design process with an Autodesk inventor are summarized in the following specifications: machine dimensions are $1625 \mathrm{~mm}$ long, $300 \mathrm{~mm}$ wide, and $1325 \mathrm{~mm}$ high; screw extruder uses a metering screw type with a diameter of $50.8 \mathrm{~mm}$ ( 2 inches) with a length: diameter ratio of $20: 1$, so the screw length is $1016 \mathrm{~mm}$, estimated throughput rate $=84 \mathrm{lb} / \mathrm{h}(42 \mathrm{~kg} / \mathrm{h})$, the motor used is $5.5 \mathrm{PK}(4 \mathrm{KW})$ with a rotation speed of 1450 .
\end{abstract}

Keywords: extruder; PET plastic; VDI221; waste processing

DOI: $10.37869 /$ ijatec.v1i3.32

Received 28 September 2020; Accepted 1 January 2021; Available online 1 January 2021

(c) The Authors. Published by IRIS. This is an open access article under the CC BY-NC-SA license @)

\section{Introduction}

The lifestyle of using plastic for daily needs product significantly increasing plastic waste. According to the Ministry of Environment (KLH) [1], Indonesia's average population produces 189 thousand tons of garbage per day. Of this amount, $15 \%$ is plastic waste or 28.4 thousand tons of plastic waste per day.

One of the popular methods for plastic waste handling is 3R (Reduce, Reuse, Recycle). Reduce is reducing the purchase or use of goods made from plastic, especially disposable items. Reuse is the repeated use of plastic-based items as much as possible. Recycle is recycling goods made of plastic. Recycling is done by processing plastic waste that does not have economic value through physical or chemical processes or both so that products can be used or sold again. Several methods and technologies offered by the government in the Master Plan for Waste Management System (SPS) masterplans include new waste utilization installations to become Briquette Energy (BE), emptying 
the location of TPSA over 10 years with a pattern of utilization of old solid materials into eco-valued products, rearranging and revitalizing land that has been emptied at TPSA, building sanitary landfills and utilizing methane gas in the further process of implementing sanitary landfills, and incinerator technology for TPSA [1]. In addition to the government's methods above, several research bodies and universities in Indonesia are also developing waste management systems such as making plastic chopping machines, processing plastic waste into fuel oil, etc. But until now, these solutions have not provided tangible benefits. To overcome this, we propose the design of a plastic waste processing machine using the extruder method. The device will process PET type plastic waste into plastic seeds.

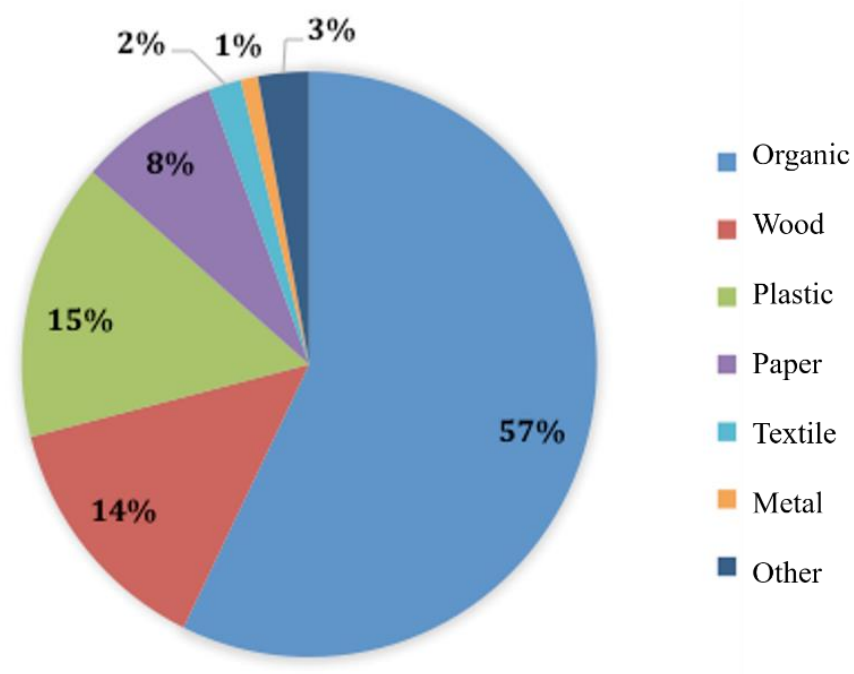

Figure 1. Percentage of various type of waste

Sustainable Waste Indonesia (SWI) conducted research in the South Jakarta area in 2017, which shows 1.3 million tons of plastic waste per year not correctly managed. For optimum waste management, reliable waste infrastructure is critical. The central and local governments have the responsibility for waste management. This waste management infrastructure includes stable waste flow connectivity, transportation, collection systems, waste processing to produce safe residues [2]. Development of Plastic Waste Shredder with Crusher System and Reel Type Cutting Cylinder is developing a plastic chopper with a crusher system and a reel-type cutting cylinder technical evaluation. The engine performance testing results at 75 RPM crusher rotation and 1450 RPM reeltype cutting cylinder engine capacity $\pm 300 \mathrm{~kg} /$ hour at $\emptyset 1.5 \mathrm{~cm}$ filter hole, with $80 \%$ grain uniformity [3]. This research aims to convert PP, PET, and PE plastic waste into oil fuel using the thermal cracking method. This research shows that PP plastic produces the least amount of fuel but with the fastest process. PET plastics do not have fuel products, and PP plastics produce energy with high calorific content [4].

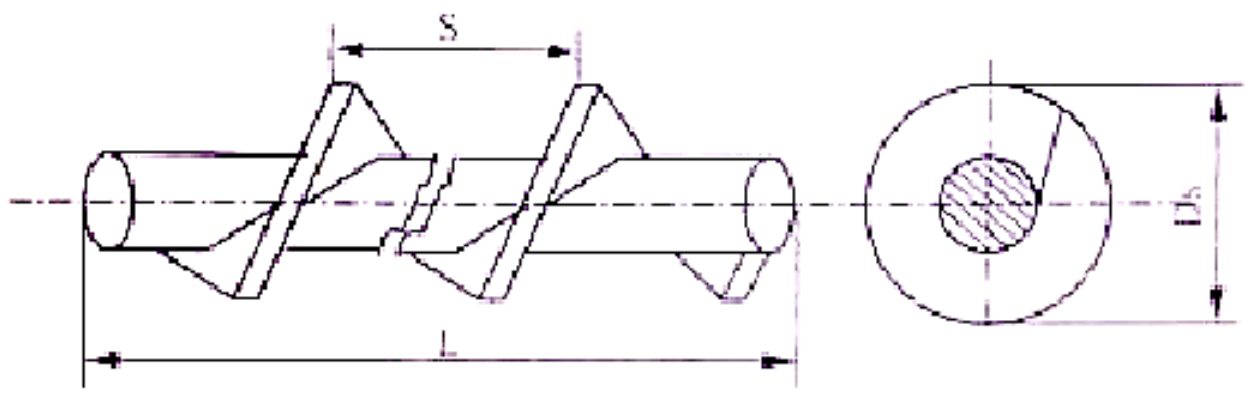

Figure 2. Screw

Waste is a raw material for making bricks. This research was conducted through an experiment of plastic waste as a raw material for bricks with various compositions and manufacturing techniques to produce environmentally friendly bricks. Based on the literature that supports the appearance of the test results, it can be measured and observed that processing plastic waste into brick material 
can increase the economic value of solving waste problems [5]. Processing plastic waste into innovative products as an economic improvement for coastal communities. This research aims to empower the community so that it can improve the community's economy [6]. This research is the creation of new jobs that are innovative from the home industry [7]. The screw is one of the main components of an extrusion machine that functions as a driving shaft, cutter, and stirring the hot polymer contained in the barrel, as shown in the Figure 2 [8].

\section{Research Methodology}

The German Engineers Association (Verein Deutscher Ingenieure / VDI) developed a product design method known as the VDI 2221 method. This method is a systematic approach to design for engineering systems and engineering products (Systematic Approach to Product and Technical System Design) described by G. Pahl and W. Beitz, Overall, the work steps contained in VDI 221 consist of several stages [9]. To achieve the research objective, a methodology was utilized, which consists of the steps of how the system was developed, as shown in Figure 3.

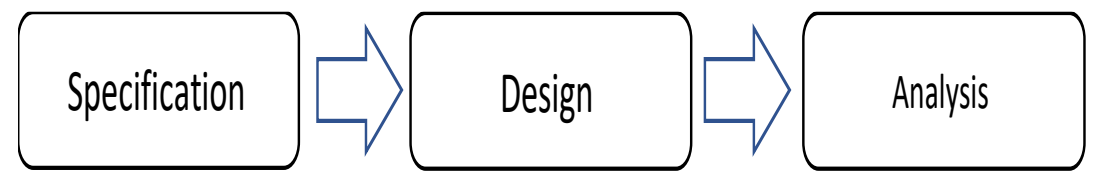

Figure 3. Research proposes methodology of plastic waste extruder machine

\subsection{Specification of the plastic waste extruder machine}

The extruder machine consists of the shredder unit, the extruder unit, the cutting unit and supported by machine frame. The configuration of extruder machine/device was described in Figure 4.

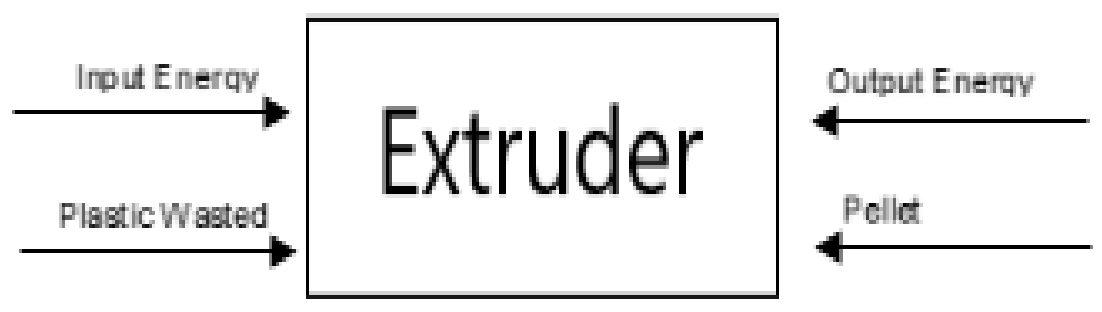

Figure 4. Specification of plastic waste extruder machine

In this case, the energy input is the motor as the primary actuator for a shredder, screw transfer, and cutter-also, the heater for melting the waste inside the extruder machine. The output is residual energy and pellet as a product.

\subsection{Design of the plastic waste extruder machine}

The extruder machine consists of the shredder unit, the extruder unit, the cutting unit, and the machine frame. The configuration of the extruder machine will be described in Figure 5.

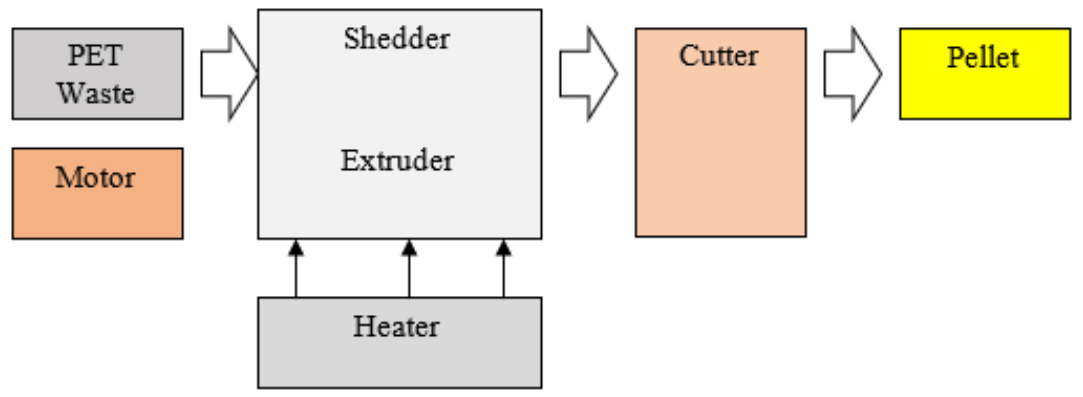

Figure 5. of Plastic Waste Extruder Machine 
To get an appropriate design and the level of conformity with the tool that needed, some formulas and equations were used, which are described as follows.

\subsection{Screw design analysis equation}

The first stage in screw design analysis and development is to determine concerning Length Ratio with Screw Diameter (L/D); from this value determination data, the value of the ratio can be obtained, which will be used in the size of the desired design screw, the percentage of the diameter value obtained is $\mathrm{L} / \mathrm{D}=20 / 1$. Furthermore, the second arc was utilized is to determine the length of each screw section, which can be obtained a measurement of feeder section (Lf) where $\mathrm{Lf}=5 / 20 \mathrm{~L}$, then select the size of compression section which can be obtained the value of the length of compression section (Lc), $\mathrm{Lc}=8 / 20 \mathrm{~L}$, after that how to determine the size of the end of metering which can be obtained $\mathrm{Lm}=7 / 20 \mathrm{~L}$. The next step is how to find the Feeder Depth value where $\mathrm{Fd}_{\max }$ $=0.2$ and the final depth of metering can be calculated By using the compression ratio formula $=\mathrm{hf} /$ $\mathrm{hm}$; and the value can be obtained, the next step is to determine the number of screws which can use the formula $S=\operatorname{tg} \alpha . \pi$ da for screw width can use the formula FW $=0.1 \mathrm{D}$.

- Throughput Rate Estimation

The second stage in the design process for the plastic waste extruder machine is to determine the throughput rate, using the following equation:

$$
\text { Rate }=2.3 \times \mathrm{D} 2 \times \mathrm{hm} \times \mathrm{SG} \times \mathrm{N} \quad(\mathrm{lb} / \mathrm{h})
$$

- Development of Barrel

The third stage is the development of the barrel, using a formula or equation like the following:

$$
P \max =\frac{6 \cdot \pi \cdot D^{2} \cdot L \cdot \eta}{H^{2} \cdot \tan \phi}
$$

- Extruder Unit Power Estimation

The next stage is the third stage in the process of designing a plastic waste extruder machine, which is the power estimation unit which uses the following equation:

$$
\mathrm{Pm}=\text { Rate } \times \Delta \mathrm{T} \times \mathrm{HV}
$$

- Development of Shredder Blade

Development of shredder Blade previous research [10], the cutting forcer of the knife can be searched by the formula:

$$
\mathrm{F}_{\text {blade }}=\mathrm{A} . \mathrm{F}_{\mathrm{s}}
$$

The results of these calculations can be found torque value on the blade.

$$
\mathrm{T}_{\text {blade }}=\mathrm{F}_{\text {blade }} \mathrm{r}
$$

- Shredder Unit Power Estimation

Determining blade power requirements for PET material can be calculated using the formula:

$$
\text { Ps }=F_{\text {Knife. }}(2 \pi . r p m) / 60
$$

- Motor Power Requirement

The most important thing in this design is how to determine the correct motor[11], in this case to get the desired motor needs in making the plastic waste extruder is to use the following formula in this section as in equation 5 .

$$
\mathrm{P}=\mathrm{Pe}+\mathrm{Ps}
$$

\section{Result and Discussion}

The shape of the screw that is designed is a metering screw, with the difference in screw depth in each feeder area, the compression section, and the end part. In screw planning, the known parameters are screw diameter (D) $=2 "(50.8 \mathrm{~mm})$. 
- Length Ratio with Screw Diameter (L/D)

The length ratio with screw diameter in the thermoplastic extrusion process is in the range of 20:1 32: 1. In this planning, a 20: 1 parameter is selected so that the length of the screw can be calculated using the formula:
$\mathrm{L} / \mathrm{D}=20 / 1$
$\mathrm{L}=20 \times 50.8 \mathrm{~mm}$
$=1016 \mathrm{~mm}$

- Length of each screw section

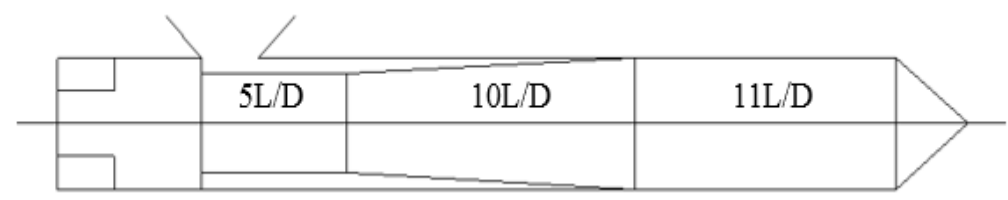

Figure 6. Each Section Length Ratio

A Screw has parts including (a) feeder part, (b) compression section, and (c) end part or metering Figure 6. The ideal feeder part of the screw with a 20: $1 \mathrm{~L} / \mathrm{D}$ ratio is between $4-5$ times the screw diameter while in the compression section is 5-10 times the screw diameter. In this design, it is determined the division of length of each screw section as shown below. Therefore, the length of each part can be calculated as shown it Table 1 .

Table 1. Calculated length of the screw plastic waste extruder machine

\begin{tabular}{lcc}
\hline \multicolumn{1}{c}{ 5L/D } & $10 \mathrm{~L} / \mathrm{D}$ & $11 \mathrm{~L} / \mathrm{D}$ \\
\hline Length of feeder section (Lf), Lf & $5 / 20 \mathrm{~L} ; 5 / 20.1016 \mathrm{~mm}$ & $254 \mathrm{~mm}$ \\
Length of compression section (Lc), Lc & $8 / 20 \mathrm{~L}$ & $8 / 20.1016 \mathrm{~mm} ; 406.4 \mathrm{~mm}$ \\
Length of the end or metering (LM), Lm & $7 / 20 \mathrm{~L}$ & $7 / 20.1016 \mathrm{~mm} ; 355.6 \mathrm{~mm}$ \\
\hline
\end{tabular}

- Feeder depth

$$
\mathrm{Fd}_{\max }=0.2 \mathrm{D}=0.2 \times 50.8 \mathrm{~mm}=10.16 \mathrm{~mm}
$$

- Final depth of metering

Compression ratio for threads with L:S is $20: 1$ ratio and generally ranges from $2: 1$ to $4: 1$. The compression ratio can be calculated by the formula:

Compression Ratio $=\mathrm{hf} / \mathrm{hm}$

$\mathrm{hm}=10.16 \mathrm{~mm} /=2.54 \mathrm{~mm}$

- Number of screws

The number of screws along the shaft can be determined by calculating the variables below first. The known parameter is the pitch screw angle which in the polymer extrusion process or thermoplastic pitch screw is equal to $17.5^{\circ}$. Furthermore, for distance between screws can be seen in the Figure 7 .

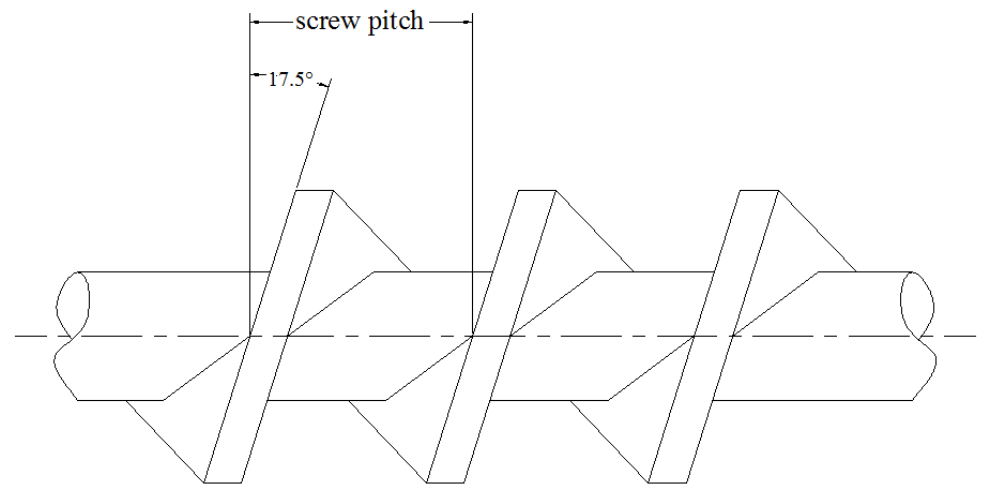

Figure 7. Screw Construction 
A calculation is obtained from the plastic waste extruder machine from the screw-making design results, which includes determining the number of screws. After the desired number of screws is received, the next step is to analyse the design results on the screw along the shaft. After that, examine the screw width to obtain the appropriate screw design results, as shown in Table 2-the analysis of screw design calculations.

Table 2. Calculation screw design and throughput rate

$\begin{array}{ll}\begin{array}{l}\text { Determine the } \\ \text { number of screws }\end{array} & \begin{aligned} \mathrm{S}=\tan 17.5^{\circ} . \pi .50 .8 \mathrm{~mm}=0.315 \pi .50 .8 \mathrm{~mm}=50,246 \mathrm{~mm} \\ \text { The amount of screw }\end{aligned} \\ \begin{array}{l}\text { ns }=\mathrm{L} / \mathrm{S} \\ \text { along the shaft }\end{array} & \mathrm{ns}=(1016 \mathrm{~mm}) /(50.25 \mathrm{~mm})=21.2 \mathrm{~mm} \\ & \mathrm{FW}=0.1 \mathrm{D} \\ \text { Screw width } & \mathrm{FW}=0.1 .50 .8 \mathrm{~mm}=5.08 \mathrm{~mm} \\ & \text { Rate }=2.3 \times \mathrm{D} 2 \times \mathrm{hm} \times \mathrm{SG} \times \mathrm{N} \quad(\mathrm{lb} / \mathrm{h}) \\ \text { Throughput Rate } & \text { Rate }=2.3 \times 2 \times 0.125 \times 0.759 \times 100=79.35 \mathrm{lb} / \mathrm{h} \\ \text { Estimation } & \end{array}$

- Stress analysis of screw extruder

Stress analysis is an analyzes of stresses and strains with force stresses that occur in materials and structures that experience physical quantities from internal and external forces that can experience material deformation [12]. The stress analysis of screw extruder can be seen in this picture below.

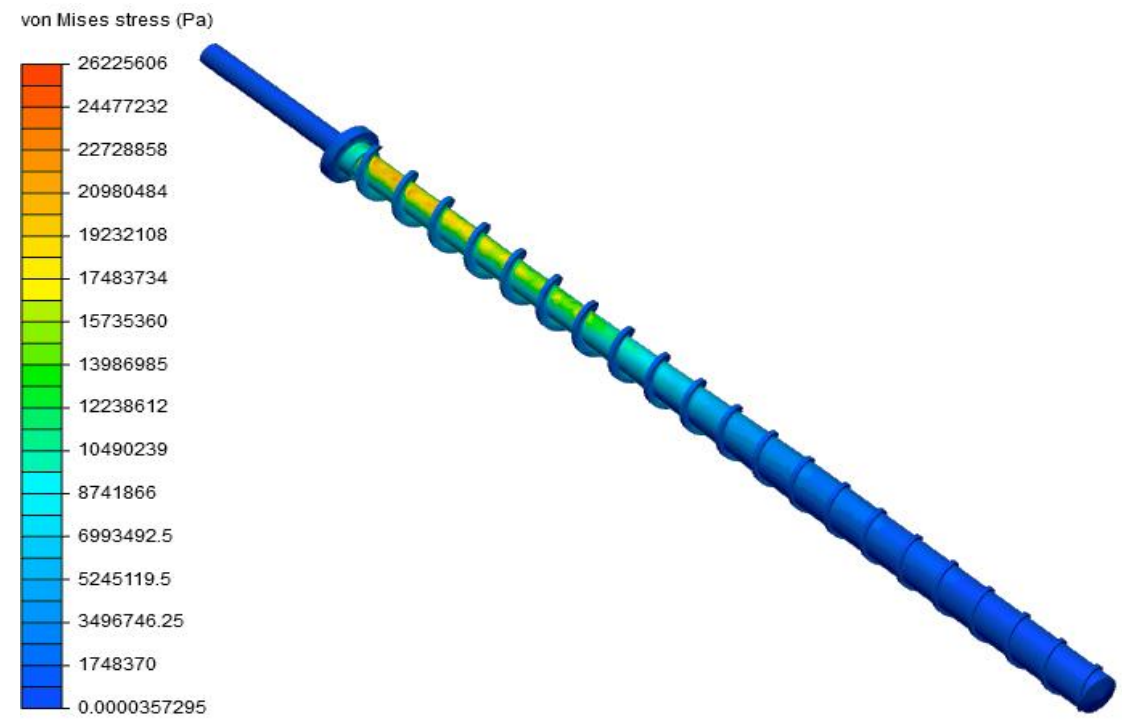

- Development of Barrel

Figure 8. Stress Analysis of Screw Extruder

In this design, the known parameters are barrel using cast iron material that has a tensile strength $\left(\sigma_{y}\right)=925 \mathrm{MN} / \mathrm{m}^{2}$ with a safety factor (SF) used is 2.5 . Screw diameter is $63.5 \mathrm{~mm}$, the screw L/D ratio is $24: 1$, the pitch screw angle (f) is 17.50 , the screw height in the metering part $(\mathrm{H})$ is 3.175 $\mathrm{mm}$. The screw rotating speed is estimated at $100 \mathrm{rpm}$ first and the maximum melt viscosity of the polymer when it melts is 500. From this parameter, the maximum pressure (Pmax) that the barrel receives is based on formula 2 .

$$
P \max =\frac{6 \cdot \pi \cdot 63 \cdot 5^{2} \cdot(24 \cdot 10) \cdot\left(\frac{100}{60}\right) \cdot 500}{3,375^{2} \cdot \tan 17 \cdot 5^{\circ}}
$$

$\mathrm{P}_{\max }=253 \mathrm{MN} / \mathrm{m}^{2}$, Von misses stress related to the yield stress of the material, in this case, is the barrel of the extruder machine. From the results of the above pressure, calculations can be calculated hoop stress and axial stress.

Circumferential stress $\left(\sigma_{1}\right)=($ Pmax. D) $/ 2 \mathrm{~h}$

Longitudinal stress $\left(\sigma_{2}\right)=($ Pmax. D) $/ 4 \mathrm{~h}$ 
A Von Misses failure will occur if

$$
\begin{aligned}
& \left(\frac{\sigma y}{F S}\right)^{2} \leq \sigma 1^{2}+\sigma 2^{2}-\sigma 1 \sigma 2 \\
& \left(\frac{925}{2.5}\right)^{2}=\left(\frac{(253) 63.5}{2 h}\right)^{2}+\left(\frac{(253) 63.5}{4 h}\right)^{2}-\left(\frac{(253)^{2}(63.5)^{2}}{8 h^{2}}\right)
\end{aligned}
$$

$\mathrm{h} \approx 12 \mathrm{~mm}$

From the calculation above the minimum barrel wall thickness is $12 \mathrm{~mm}$.

- Stress Analysis of the Barrel

The barrel on extruder machines is subjected to circumferential stress and longitudinal stress. The stress analysis of the barrel can be seen in this picture below.

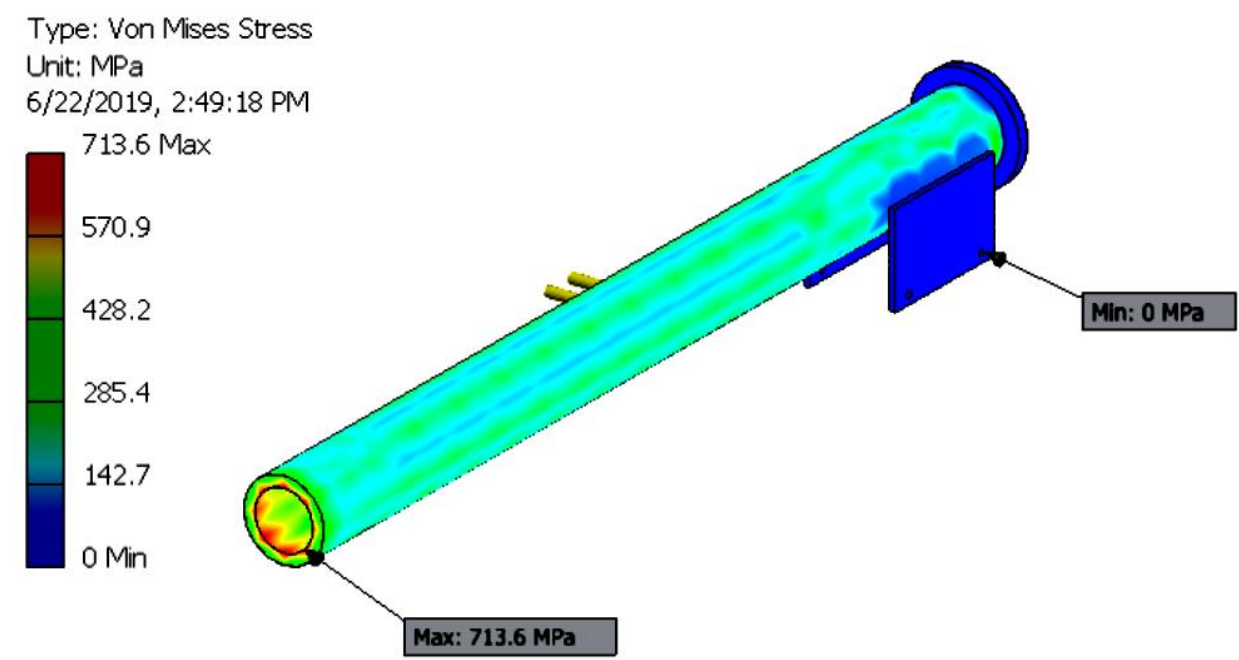

Figure 9. Stress analysis of barrel

- Extruder Unit Power Estimation

To calculate plan power, formulas can be used formula 2, obtained the calculation results on the determination of the extruder unit power estimation, where:

$\Delta \mathrm{T} \quad$ : extrusion temperature difference - room temperature $\left(465.5^{\circ} \mathrm{F}-75^{\circ} \mathrm{F}=390{ }^{\circ} \mathrm{F}\right)$

$\mathrm{HV}$ : heat value $(\mathrm{PE}=0.55 \mathrm{BTU} / \mathrm{lb} \circ \mathrm{F})$

$\mathrm{Pm} \quad: 54.55 \mathrm{lb} / \mathrm{h} \times 390 \circ \mathrm{F} \times 0.55 \mathrm{BTU} / \mathrm{lb} \circ \mathrm{F}$

$\mathrm{Pm}: 11700,975 \mathrm{BTU} / \mathrm{lb}{ }^{\circ} \mathrm{F}=11700,975 \mathrm{BTU} / \mathrm{lb}{ }^{\circ} \mathrm{F} \times 0,000393=4.59 \mathrm{PK}(3.42 \mathrm{KW})$

- Development of Shredder Blade

The designed blade is a type "S" with a hole in the center for mounting a blade on a rotating shaft [13]. The blade has two blades where the front and rear sides of the blade have an $80^{\circ}-100^{\circ}$ angle to the body blade. The illustration of the blade can be seen in the picture below.
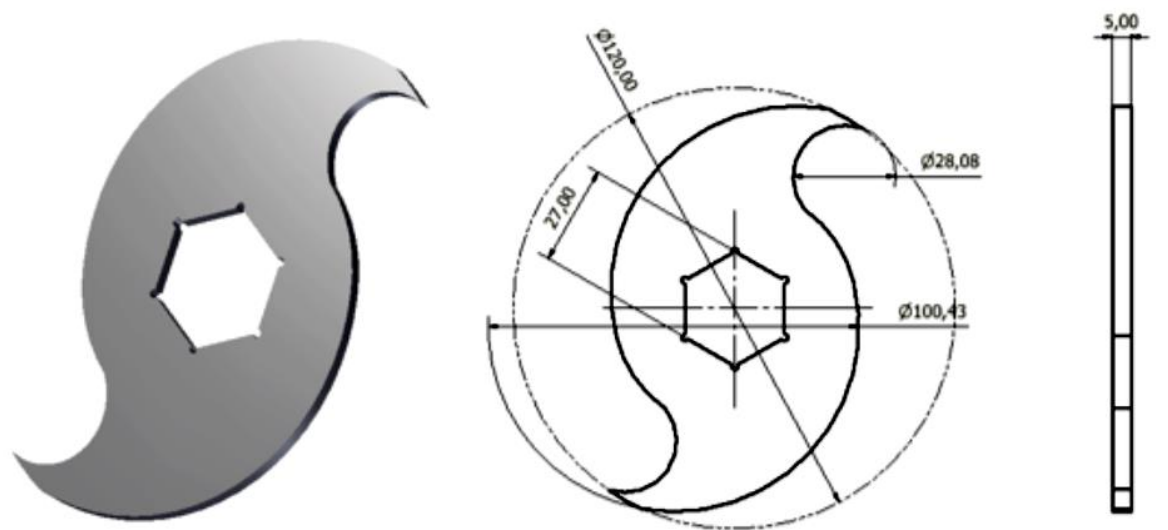

Figure 10. Blade Construction 


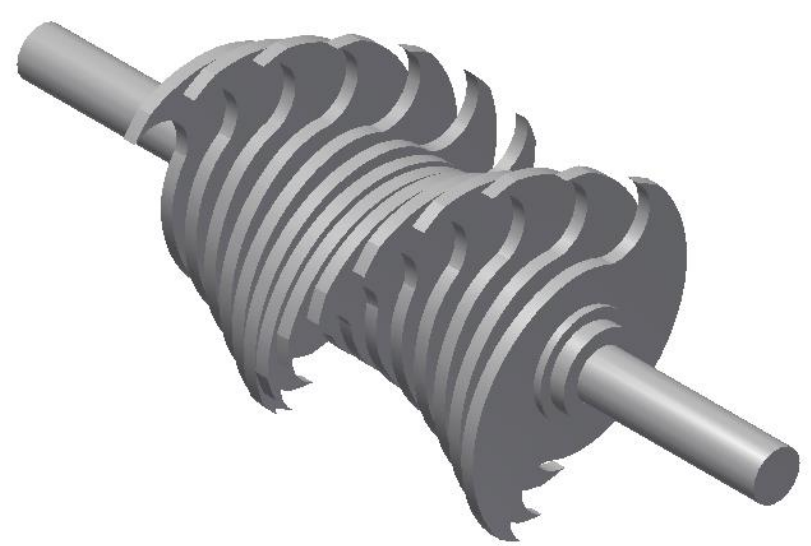

Figure 11. Assembly of blades connected to a shaft

The cutting forcer of the knife can be obtained by the formula 1.3 and the result of these calculations can be found torque value on the blade:

$F_{\text {blade }}=65.45 \mathrm{~cm}^{2} .12 .6 \mathrm{Kgf} / \mathrm{cm}^{2}=824.64 \mathrm{Kgf}=8087 \mathrm{~N}$

$\mathrm{T}_{\text {blade }}=8087 \mathrm{~N} .0 .06 \mathrm{~m}=485.22 \mathrm{Nm}$

- Stress Analysis of the Blade

The stress analysis of the blade can be seen in this picture below.

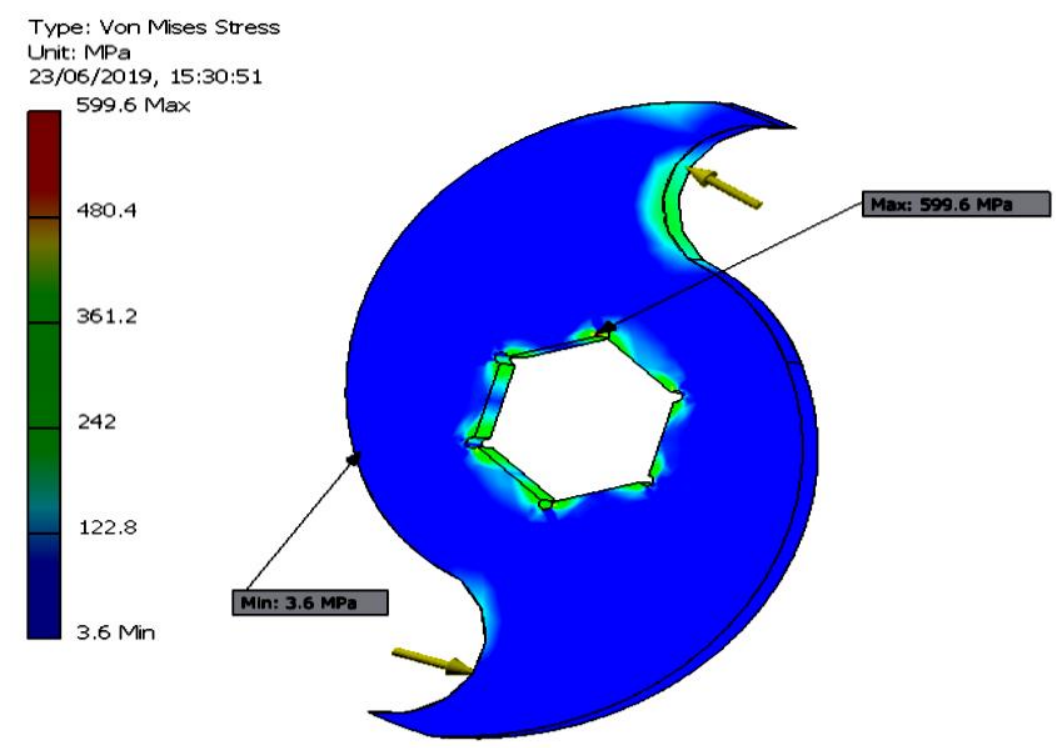

Figure 12. Stress Analysis of Blade

- Shredder Unit Power Estimation

Determining blade power requirements for PET material can be calculated using the formula:

Ps $=F_{\text {Knife. }}(2 \pi . r p m) / 60$

$\mathrm{Ps}=485.22 \mathrm{Nm} .(2 \pi 100) / 60=5078 \mathrm{~W}(5 \mathrm{~kW})$

- Motor Power Requirement

The need for a motor in develop this Plastic Waste Extruder Machine has a vital role, in connection with the need for a motor to rotate the shaft when plastic waste has entered the heater on the previously designed screw, based on formula 1.5 can analysis need results motor power requirement.

$$
\mathrm{P}=3.42 \mathrm{~kW}+5 \mathrm{~kW}=8.42 \mathrm{~kW}
$$


- Isometric design plastic waste extruder machine

From several calculation analyzes of several components, the following is the design of a plastic waste extruder machine that has been made isometrically using Autodesk Inventor software, can be seen in Figure 13.

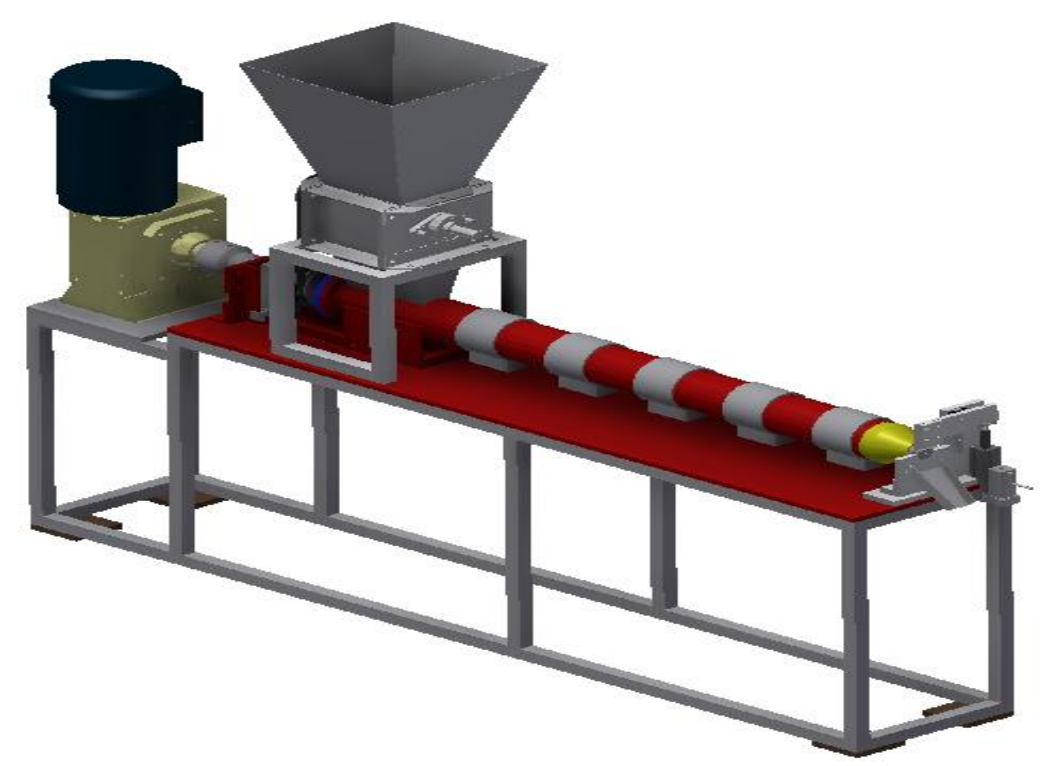

Figure 13. Design final plastic waste extruder machine

\section{Conclusion}

The design of the plastic waste extruder machine can handle the problem of increasing plastic waste. The design consists of several units: shredder unit, extruder unit, cutter unit, and machine frame. The shredder unit serves to destroy plastic waste that is still intact in pieces before being processed in the extruder unit. The extruder unit functions to melt PET waste to be extruded using a screw. The cutter unit works to cut processed extrusion waste into pellet granules. The engine frame is used to support the entire engine unit. The results of the Plastic Waste Extruder Machine design process with an Autodesk inventor are summarized in the following specifications; Machine dimensions are 1625 $\mathrm{mm}$ long, $300 \mathrm{~mm}$ wide, and $1325 \mathrm{~mm}$ high; screw extruder uses a metering screw type with a diameter of $50.8 \mathrm{~mm}$ ( 2 inches) with a length: diameter ratio of $20: 1$, so the screw length is $1016 \mathrm{~mm}$, estimated throughput rate $=84 \mathrm{lb} / \mathrm{h}(42 \mathrm{~kg} / \mathrm{h})$, the motor used is $5.5 \mathrm{PK}(4 \mathrm{KW})$ with a rotation speed of $1450 \mathrm{rpm}$.

\section{Acknowledgment}

The authors acknowledge the Universitas Mercu Buana for the research grant of scheme Kerjasama Dalam Negeri (KDN).

\section{References}

[1] DKI Tata Ruang dan Lingkungan hidup, “Grand Design Sistem Pengololaan Sampah Pemprov DKI Jakarta," Jakarta, 2016.

[2] Indra suara pembaruan, "Dua Kota Indonesia Produksi 1, 3 Juta Ton Sampah Jakarta dan Surabaya," Suara Pembaruan, Jakarta, p. 2, May-2018.

[3] I. Nur, "Pengembangan Mesin Pencacah Sampah / Limbah Plastik," J. Eng. Appl. Sci., vol. 1, no. 8, p. 4, 2014.

[4] U. B. Surono, "Pengolahan Sampah Plastik Jenis PP , PET dan PE Menjadi Bahan Bakar Minyak dan Karakteristiknya," Mekanika, vol. 1, no. 2, pp. 32-37, 2016.

[5] T. Pramono, S. A., \& Watiningsih, "Panorama Village Red Brick Making," Semnas Entren., pp. 197208, 2014.

[6] R. Jones et al., "Waste plastic extruder : literature review," Michingan, 2, 2004. 
[7] S. Arico, Z., \& Jayanthi, "Processing Plastic Waste Into Creative Products To Improve The Economy Of Coastal Communities," J. Pengabdi. Kpd. Masyaraka, vol. 1, no. 1, p. 10, 2018.

[8] H. C. Chandara, Sunjoto, and Sarto, "Plastic Recycling in Indonesia by Converting Plastic Wastes (PET, HDPE, LDPE, and PP) into Plastic Pellets," ASEAN J. Syst. Eng., vol. 3, no. 2, pp. 65-72, 2016.

[9] T. Tomiyama, P. Gu, Y. Jin, D. Lutters, C. Kind, and F. Kimura, "Design methodologies: Industrial and educational applications," CIRP Ann. - Manuf. Technol., vol. 58, no. 2, pp. 543-565, 2009.

[10] S. K. Mandal, B. Bhattacharyya, S. Mukherjee, and P. Chattopadhyay, "Design \& Development of Rotavator blade: Interrogation of CAD Method," Int. J. Sci. Res. Knowl., no. October, pp. 439-447, 2013.

[11] O. I. Okunola, D. A. Oyebade, and O. O. Olanrewaju, "Development of Shredding and Washing Machine for Polyethylene Terephthalate (Pet) Bottles Pelletizer," Int. J. Eng. Sci. Appl., vol. 3, no. 2, pp. 1-8, 2019.

[12] M. R. Horne, "Formulas for stress and strain," J. Mech. Phys. Solids, vol. 3, no. 1, 2008.

[13] R. et al Khurmi, "Theory of Machines," in Khurmi,R.et all, 14th ed., New Dehli: S. Chand \& Co. Ltd, 2005. 